\title{
LA METAPOETICA VIRGILIANA
}

This paper intends to demonstrate that Aristeus' and Orpheus' epyllia (Georg. IV) establish a genuine metapoetics, in which by using a mythical discourse,

Virgil explains his conception of the function of poets and poetry.

Taking Virgilian text as a prime source of information, a series of relationships are laid down between the four books of Georgics, and between Georgics and the rest of Virgilian production. The relationship agricola-poeta makes explicit on a triple level - theoretical, poetical, and mythical - the essence of the being and doing of poets in particular, and of men in general.

Varios y de diversa índole son los interrogantes que plantean al lector los epyllia de Aristeo y Orfeo que aparecen en el canto IV de Geórgicas. La crítica ha producido rios de tinta procurando una respuesta y los resultados son muchos y no siempre muy satisfactorios. Nosotros intentaremos alistarnos también en ese ya numeroso ejército de comentaristas, pero lo haremos tomando como soporte teórico la idea de que toda obra es un sistema en el cual cada uno de los elementos cumple una función respecto de los demás y de la totalidad resultante, de manera tal que la aludida respuesta debe rastrearse en el comportamiento mismo de ese sistema. Además de ello, Geórgicas es parte integrante de un sistema significante mayor, el constituido por toda la producción virgiliana, con el cual guarda relaciones intertextuales que, a nuestro juicio, la alumbran y explicitan. En razón de ello, la intratextualidad y la intertextualidad así definidas operarán para nosotros como relaciones privilegiadas frente a cualquier tipo de lazo extratextual.

\section{Los protagonistas}

Para definir entonces la función y el sentido de estos epyllia dentro de Geórgicas analizaremos, en primer lugar, la presentación que hace Virgilio de los protagonistas. 
1.1. Aristeo

Aristeo es el homo rusticus por antonomasia:

... cultor nemorum, cui pinguis Ceae

ter centum niuei tondent dumeta iuuenci $(G$. I 14-15)

En etiam hunc ipsum uitae mortalis honorem, quem mihi uix frugum et pecudum custodia sollers omnia temptanti extuderat, te matre, relinquo.

Quin age et ipsa manu felicis erue siluas;

fer stabulis inimicum ignem atque interfice messis; ure sata et ualidam in uitis molire bipennem, tanta meae si te ceperunt taedia laudis ( $G$. IV 326-332)

\subsection{Orfeo}

En Geórgicas IV se dice de Orfeo que:

illum ... / ...

fleuisse et gelidis haec euoluisse sub antris

mulcentem tigris et agentem carmine quercus (507-510)

Este efecto que su canto produce sobre la naturaleza y que también aparece en Bucólicas (cf. III 46) se hace extensivo a los habitantes del mundo inferior como se ve en los versos 471-484 del mismo canto IV. Así entonces si Aristeo es el homo rusticus, Orfeo es el vate, el poeta.

\subsection{El rusticus y el poeta en Geórgicas}

Duckworth' ha señalado ya el hecho de que en los finales de los cuatro cantos de Geórgicas alternan guerra, paz, muerte y regeneración, estableciendo así una suerte de vinculación temática general que enlazaría los libros pares e impares entre sí. Esta atinada observación nos sirve de apoyo para otra instancia de enlace que proviene precisamente de las definiciones de Aristeo y Orfeo como rusticus y poeta respectivamente.

En efecto, al final del canto II, en un bellísimo pasaje que comienza en el verso 458, Virgilio establece una compleja relación entre el agricola y el poeta a través de la oposición ignarus-gnarus. El agricola participa de un orden constituido por la concordia (procul discordibus armis, v. 459), la iustitia (... extrema per illos / iustitia excedens terris uestigia fecit, vv. 473-474) y la pietas (sacra deum sanctique patres, v. 473), orden

G. E. Duckworth, "Vergil's Georgics and the Laudes Galli», AJPh 80, 1959, p. 225 ss. 
que está encarnado en la iustissima tellus (v. 460) y que lo eleva a su condición de fortunatus (fortunatus et ille deos qui nouit agrestis, v. 493), si bien desconoce las razones o causas de ese orden. Ese conocimiento pertenece al poeta. Su labor consiste en saber (unde ... qua ui ... / quid ... / ... quae ... mora ..., vv. 479-482) aquello que las Musas han de enseñarle (me ... Musae / ... / accipiant ... et ... monstrent, vv. 475-477) así como lo hicieron con Hesíodo (... hos tibi dant calamos, en accipe, Musae, / Ascraeo quos ante seni, B. VI 69-70). Ese saber del poeta, que es un saber acerca del cosmos (cf. G. IV 476-482) lo elevará a la condición de felix (felix qui potuit rerum cognoscere causas, v. 490). Si acaso el poeta no pudiera acceder a ese conocimiento, si no pudiera accedere naturae partis (v. 483) permanecerá inglorius (v. 486), pero siendo un campesino (rura mihi et rigui placeant in uallibus amnes, / flumina amem siluasque, vv. 485-486). De esta manera aquí, en el final del canto II, se explicita en un nivel que podríamos denominar teórico-especulativo, una relación entre el agricola y el poeta que aparecen emparentados por pertenecer ambos a un mismo orden de concordia, iustitia y pietas y se diferencian por su condición de ignarus-gnarus ${ }^{2}$ respecto de las causas de ese orden ${ }^{3}$.

Ahora bien, en esta formulación teórica, existe la posibilidad de que el poeta no alcance ese conocimiento y permanezca inglorius; sin embargo, el propio Virgilio muestra en el canto IV que sí cree haber cumplido ese objetivo, pues dice:

In tenui labor; at tenuis non gloria, si quem numina laeua sinunt auditque uocatus Apollo (6-7)

Nos interesa rescatar un dato más en esta elaboración de la relación agricola-poeta que presenta Virgilio al final del canto II y es la mención de Dicteo en el verso 536 (ante etiam sceptrum Dictaei regis) que nos lleva a vincular todo este pasaje con el de I 125-146 donde se relata el origen del labor humano. Allí, en el canto I, Virgilio dice que aquella concordia entre el hombre y la tierra era, en un tiempo anterior al reinado de Júpiter (ante Iouem, v. 125), una relación unilateral en la que

2 Esta relación entre el poeta, que sabe por boca de los dioses, y el campesino aparece, además, en la apertura misma de la obra. Alli Virgilio, luego de invocar a las divinidades campestres, dispensadoras de sabiduria, y a César dice: ignarosque uiae mecum miseratus agrestis / ingredere (1 41-42), aludiendo con toda claridad a que él, como poeta, puede enseñar a los ignaros agrestis lo que éstos desconocen.

${ }^{3}$ Por otra parte, la pareja agricola-poeta, encarnada en la tellus se opone al urbanus del cual se predica la falta de concordia, iustitia y pietas en los versos 459-499 y 500-512 de este mismo canto. 
el hombre actuaba como receptor pasivo de los bienes naturales (ipsaque tellus / omnia liberius, nullo poscente, ferebat, vv. 127-128). Pero Júpiter, ut uarias usus meditando extunderet artis (v. 132) provoca una egestas (v. 146) y asi el hombre con su labor improbus (labor omnia uicit / improbus, vv. 145-146) da origen a esas uariae ... artes (v. 145) que instauran una relación homo-tellus nueva en la que el hombre es parte activa y responsable. Esta acción de Júpiter origina la aparición del agricola, que se yergue así como el prototipo del hombre civilizador, en la medida en que explicita una relación homo-tellus que es en sí y por sí originaria. El hombre con su labor participa de ese orden cósmico, cumple su parte en esa concordia y en esa iustitia. Este pasaje del canto I, leído en relación con lo expresado por Virgilio en el final del II, permite explicarnos por qué el poeta cree haber cumplido su cometido (tenuis non gloria, IV 6). Si lo que otorga la gloria al poeta es que, inspirado por la divinidad, cante un origen, conozca y celebre las causas, Virgilio ha logrado esa meta con Geórgicas ya que, al cantar la agricultura y la ganadería, está celebrando una relación homo-tellus que es la esencia del hombre, que lo define como tal.

\section{Los relatos}

Revisaremos ahora los dos epyllia para observar el comportamiento de sus protagonistas, a quienes Virgilio define, en el plano teórico, al final del libro II.

\subsection{El epyllion de Aristeo}

Aristeo, el homo rusticus, sufre una egestas: la pérdida de sus enjambres. Tal como nos lo informa el canto II, por ser un agricola no está en condiciones de conocer las causas de esa pérdida y para ello debe recurrir a Proteo, el vate. Así, en IV 396-397, Cirene dice a su hijo:

Hic tibi, nate, prius uinclis capiendus, ut omnem expediat morbi causam euentusque secundet.

Así, por boca de Proteo, conoce Aristeo que su acto ha producido una ruptura en el equilibrio cósmico, ha alterado la concordia. Es en este sentido muy sugerente la manera como Virgilio enfatiza la reacción de la naturaleza (vv. 460-463) mencionada aun antes que la del mismo Orfeo, señalando de este modo cómo es el cosmos todo el que resulta alterado y no sólo el hombre. El desconocimiento de Aristeo está a su 
vez marcado por el plano sintáctico. Observamos que, en lo referente a su «culpa»:

- Aristeo aparece como sujeto agente de un único verbo (luis, v. 455) que sin duda señala la necesidad de expiar una falta, pero no aparece como sujeto agente de ningún verbo que indique la comisión de la falta.

- De las restantes apariciones, dos (te... exercent, v. 454, y tibi ... | ... | ... suscitat, vv. 454-456) lo muestran como objeto de acciones realizadas por Orfeo que estarían motivadas en el texto por los sintagmas magna ... comissa (v. 454) y rapta ... pro coniuge (v. 456) que tienen en común el ser expresiones pasivas sin mención expresa del agente.

- La tercera y última aparición (te fugeret, v. 457) lo muestra como objeto de la acción de huir de Eurídice, la cual opera sintácticamente como circunstancia temporal del episodio puntual de la muerte.

- Finalmente, el hecho específico de la muerte no se menciona de manera expresa, sino que tan sólo aparece aludido en el moritura del verso 458 .

El plano sintáctico parecería estar indicando, pues, un intento, por parte de Virgilio, de esfumar la responsabilidad de Aristeo cuyo castigo se califica precisamente como haudquaquam ob meritum (v. 454), todo lo cual resulta enfatizado por el tratamiento opuesto que recibe, como veremos, la responsabilidad de Orfeo.

El agricola Aristeo es entonces, como tal, ignarus, pero en la medida en que su acto afecta a la relación homo-tellus aparece la egestas. Esta egestas, tal como aprendimos en el relato del canto I, supone el cumplimiento de un labor que a su vez dará origen a una ars: la bugonia. Efectivamente, al introducir este epyllion dice Virgilio:

Quis deus hanc, Musae, quis nobis extudit artem?

Vnde noua ingressus hominum experientia cepit? (315-316)

Con el relato de Orfeo y Eurídice, Proteo, el vate, enseña a Aristeo la causa de su mal (haec omnis morbi causa, v. 532), pero, al hacerlo, le enseña, además, la relación homo-tellus como constitutiva de una concordia que se quiebra o mantiene por los actos del hombre, tal como aparecía en el canto II. Esa concordia tiene así una praxis, expresada en la obra toda; una teoría, el canto II, y una formulación mítica, el canto IV. El conocimiento de la praxis pertenece al agricola, los otros dos al poeta, en tanto vehículo de la divinidad y en cuanto manifiesta las causas primeras de aquélla. 


\subsection{El epyllion de Orfeo}

Orfeo, según habíamos concluido, es el poeta por antonomasia. En Eneida lo hallamos habitando los Campos Elíseos, ceñido con la banda blanca, junto a los sacerdotes, los vates, los que dijeron palabras dignas de Febo, junto a Museo, su discípulo y conductor de Eneas (cf. VI 637 664). Esperariamos, entonces, que el Orfeo de Geórgicas fuera felix ya que, como poeta, es un conocedor de las causas primeras. Sin embargo lo que encontramos es un Orfeo miserabilis (v. 454), incautus (v. 488), immemor (v. 491), presa de la dementia (v. 488) y el furor (v. 495). Esta fuerte predicación negativa está reforzada por la mayor extensión asignada por el poeta al episodio de la violación del tabú y al de la pérdida, conjunto éste que señala un marcado contraste con la brevedad y elusión que caracterizan la narración de la «falta» de Aristeo. Esto es particularmente notable puesto que el alocutario de este discurso de Proteo es Aristeo. Las tintas están aquí cargadas sobre la "falta» de Orfeo. Éste, a diferencia de Aristeo, es un poeta, y por lo tanto sabe y conoce la ley (hanc ... legem, v. 487); a partir de ello su acto (rupta tyranni / foedera, vv. 492-493) se transforma de un "error» en una "culpa» de la cual es plenamente responsable. El hecho de ser gnarus es lo que permite la aparición del incautus y del immemor, situación a la que es arrastrado por el furor y la dementia.

Ahora bien, si recurrimos al resto del corpus virgiliano, veremos que estos calificativos aparecen alli referidos a personajes que como Dido (En. IV 70, 78, 433, 501, etc.), Pasífae (B. VI 47), Pigmalión (En. I 348), Galo $(B . X 38,60)$ y el mismo Coridón (B. II 60, 69), entre otros, son presa de una pasión que los enajena y destruye y aparecen en un contexto lexical vinculado con el campo semántico de la crueldad y la desmesura. La predicación nos llevaría, por lo tanto, a identificar a Orfeo con estos personajes y sin embargo ellos, en Eneida VI, no están de ningún modo en los Campos Elíseos, sede de Orfeo, sino en el lugar donde moran quienes durus amor crudeli tabe peredit (v. 442) y curae non ipsa in morte relinquunt (v. 444). Nos preguntamos, pues, dónde reside la diferencia que le hace elegir a Virgilio ubicaciones tan disímiles para aquellos que parecerían igualmente condenados.

Para responder a esto analizaremos otros aspectos del epyllion. Cuando Virgilio presenta a Cirene en la morada de las ninfas, Clímene está cantando:

Inter quas curam Clymene narrabat inanem

Volcani Martisque dolos et dulcia furta

aque Chao densos diuom numerabat amores (345-347) 
La ninfa que conduce a Aristeo hasta su madre es, a su vez, Aretusa, elección sugerente por parte del poeta porque ella misma ha sido objeto de una persecución amorosa y porque su nombre, que aparece una sola vez más en todo el corpus virgiliano, evoca la Bucólica X creando una serie de resonancias intertextuales ${ }^{4}$ :

- Esa Bucólica está dedicada a Galo, que es el poeta a quien en la VI Lino le advierte que debe oír a las Musas que guiaron a Hesíodo:

\author{
ut Linus ... / ... \\ dixerit: "hos tibi dant calamos, en accipe, Musae \\ Ascraeo quos ante seni, quibus ille solebat \\ cantando rigidas deducere montibus ornos. \\ his tibi Grynei nemoris dicatur origo, \\ ne quis sit lucus quo se plus iactet Apollo" (67-73)
}

- Por el amor de Lícoris, Galo abandona su deber de poeta (iam neque Hamadryades rursus neque carmina nobis / ipsa placent, X 62-63) y por eso se le pregunta quid insanis? (v. 22). Ese amor que es crudelis (v. 29), indignus (v. 10) e insanus (v. 44) se define como un furor (v. 60) y todo lo vence (omnia uincit Amor, v. 69), incluso la poesía.

- Ese furor produce una conmoción en la naturaleza (vv. 12-16), en los hombres (vv. 19-20) y en los dioses (vv. 21-27) .

Esta serie de ecos señalan que Aretusa, al evocar a Galo, evoca el amor como furor en sí y en relación con la producción poética. El furor está de este modo presente no sólo en Orfeo sino en todo el curso de los epyllia. Por el furor de Aristeo muere Eurídice, por el furor de Orfeo (v. 453) y de las Ninfas (v. 536) mueren las abejas, por el furor Orfeo pierde a su esposa, por el furor de las mujeres tracias muere el mismo vate $^{6}$. El furor, el amor así concebido como fuente de saeuitia y de discordia, aparece también en Geórgicas III:

4 La presencia de Bucólicas en Geórgicas está, por otra parte, incitada por el mismo Virgilio en la evocación de IV 563-566, cierre de la obra.

5 Los elementos naturales convocados (Ménalo, Liceo), las divinidades agrestes (Pan y Silvano) y las Ninfas están también presentes en la apertura de Geórgicas. Así el cierre de Bucólicas y el inicio de Geórgicas se evocan preludiando una oposición entre poesía y furor que se desarrollará a lo largo de toda la obra.

- La presencia del furor en estos relatos está resonando incluso en las historias del propio Aristeo, que es el fruto de una unión determinada por un rapto perpetrado por Apolo, y de Prosérpina. No olvidemos que los romanos habian identificado a esta diosa con Perséfone (cf. $G$. I 39), quien sufre un rapto por el amor de Plutón que acarrea la esterilidad de los campos a causa del dolor de su madre Deméter. 
Omne adeo genus in terris hominumque ferarumque et genus aequoreum, pecudes pictaeque uolucres in furias ignemque ruont: amor omnibus idem.

Tempore non alio catulorum oblita leaena saeuior errauit campis nec funera uolgo tam multa informes ursi stragemque dedere per silvas, tum saeuos aper, tum pessima tigris (242-248)

Esta equivalencia entre amor, furor y discordia, es, por lo demás, una constante en el universo virgiliano cuyo horizonte se va ampliando desde la experiencia individual de Coridón, a la experiencia cósmica del agricola Aristeo y se cierra con la experiencia individual-cósmico-histórica de Eneas. Esa experiencia, aun en los que como Eneas habitarán sin duda los Campos Elíseos, supone necesariamente en Virgilio pérdida, muerte y sufrimiento ${ }^{7}$. El furor es, en tanto estado de enajenación, el signo determinante de la Discordia, tomada como entidad: Discordia demens dice Virgilio en En. VI 282 cuando describe a los habitantes que moran en los umbrales del Orco.

De este modo el hombre que, presa del furor, provoca la discordia sufre una egestas y debe realizar un labor. La ceguera del furor expresada por el poeta Galo en el omnia uincit Amor (B. X 69) debe ser reemplazada por la sabiduría del labor omnia uicit / improbus expresado en Geórgicas (I 145-146). Así Aristeo, que con su furor provoca una discordia, sufre una egestas y realiza un labor con el cual restituye la concordia y recupera el bien perdido. Así Orfeo, que con su furor viola un pacto divino, sufre una egestas: perder a Eurídice. Sin embargo su falta, a diferencia de la de Aristeo, no es un error sino una culpa porque es gnarus y, por lo tanto, al igual que Eneas ${ }^{8}$ no puede recuperar el bien perdido. Como Eneas sigue sufriendo ${ }^{9}$ pero, a diferencia de Galo, Orfeo persevera en la poesía:

fleuisse et gelidis haec euoluisse sub antris

mulcentem tigris et agentem carmine quercus (509-510)

7 En la Eneida la relación furor-pérdida es una constante que se observa no sólo en Eneas y, desde luego, en Dido, sino en Béroe, Amata, Camila, Turno y en la misma Juno, por citar los ejemplos más sobresalientes.

${ }^{8}$ Cabe recordar que Mercurio, al advertir a Eneas acerca de su obligación de abandonar Cartago, le dice regni rerumque oblite tuarum! (IV 267) donde sentimos resonar el immemor que se predica de Orfeo.

${ }^{9}$ Eneas sufre incluso cuando encuentra a Dido en el Hades: demisit lacrimas ( $v$. 455), lacrimasque ciebat (v. 468) y prosequitur lacrimans (v. 476), y es notable la insistencia de Virgilio en este dolor. 
El contenido de esa poesía parecería reducirse, a primera vista, a sus lamentos amorosos y mantenerse, por lo tanto, dentro de un plano estrictamente individual. Sin embargo, debemos prestar especial cuidado a la reacción que ese canto provoca en la Naturaleza: mulcentem tigris et agentem ... quercus ( $v$. 510) la cual nos lleva a considerar otros elementos dentro del corpus virgiliano. En efecto, en ese sistema significante, esta predicación referida al poder de un canto aparece atribuida en Bucólica VI a Sileno y a Hesíodo:

[Sileno]: $\quad \ldots$ simul incipit ipse.

Tum uero in numerum Faunosque ferasque uideres ludere, tum rigidas motare cacumina quercus (26-28)

[Hesiodo]: ... quibus ille solebat cantando rigidas deducere montibus ornos (70-71)

Para ambos se especifica el contenido del canto: el de Hesíodo ha sido Grynei nemoris ... origo (v. 72), el de Sileno es la bucólica misma que muestra el origen del mundo a partir de una formulación epicúrea. Ambos cantos son, por lo tanto, cantos cosmogónicos, ambos celebran un origen, de modo que parecería ser ése el tipo de canto que, en el sistema virgiliano, produce tales efectos de conmoción y emoción en la naturaleza. Debe agregarse además que ese canto produce un conocimiento (carmina quae uoltis cognoscite, B. VI 25) y ese conocimiento eleva a quien lo posee a la condición de beatus (omnia quae Phoebo quondam meditante beatus / audiit Eurotas, v. 82). Este adjetivo beatus nos remite precisamente a las sedes beatas que es la denominación que reciben los Campos Elíseos en su descripción de Eneida (VI 637-639).

De toda esta información suministrada por Virgilio podemos concluir que Orfeo es, como Hesíodo, un vate, un sacerdote de las Musas, un poeta cuya palabra consiste en un canto cosmogónico que, como tal, trasciende la esfera humana y verbaliza una instancia superior, una palabra que transfigura el $\operatorname{cosmos}^{10}$. En razón de este canto existe para Orfeo un lugar en los Campos Eliseos y se le confiere la inmortalidad.

\section{Conclusiones}

A partir del análisis efectuado creemos estar en condiciones de concluir que los epyllia de Aristeo y Orfeo son la formulación mítica de los

${ }^{10}$ Merece mencionarse también que en $B$. IV 55-57 se equipara a Orfeo con Lino (a quien en $B$. VI 67 se define como diuino carmine pastor) en función de sus respectivos padres inspiradores, una Musa para Orfeo, el mismo Apolo para Lino, siendo estas divinidades las únicas que, en la obra virgiliana, pueden conceder la condición de uates. 
planteamientos teórico-especulativos expresados por Virgilio al final del canto II y que la suma de estos dos discursos constituye una metapoética, una verdadera ars poetica que explicita la concepción virgiliana respecto de la poesía en general y de la suya en particular. Orfeo y Aristeo, representantes en el mundo mítico del poeta y el agricola "humanos» del canto II, muestran en su historia el funcionamiento de la relación que los une entre sí y con la naturaleza. Ambos son parte del cosmos y como tal pueden alterar esa delicada concordia discordium que lo caracteriza. Son, para Virgilio, dos caras de una misma moneda cuyo sello debe ser la observancia de esa concordia originaria encarnada en la iustissima tellus. Son, por lo tanto, dos opciones de una misma forma de vida que se opone a la discordia entendida como el predominio del furor. El labor del campesino, su función dentro de esa concordia es una praxis de la que no puede dar razón. El labor del poeta y de la poesía misma es conocer y cantar las causas de esa concordia. El ejercicio poético, así entendido, es una forma de vida, una actitud, que en tanto explicita esa relación homo-natura-pietas se opone a la poesía como exteriorización del furor. En rigor de verdad, y tal como lo demuestra Galo, la poesía del furor es la anulación de la poesía. La poesía puesta al servicio del furor no sirve para recomponer la concordia y por eso Orfeo no puede, a pesar del poder de su canto, recuperar a Eurídice. La poesía es y debe ser fundamentalmente un labor improbus y el labor más duro y dificil del hombre es, para Virgilio, el de vencer su propio furor en pos de su propio destino. Quedan así sentados, en esta singular ars poetica, los tres ejes medulares del discurso virgiliano: labor, furor y fatum, que alcanzarán su más formidable expresión en la gesta del héroe Eneas".

Ana Maria Pendás de Buzón Alicia SChniebs de Rossi

$"$ Es muy elocuente, en este sentido, el comienzo de la Eneida en el que Virgilio enuncia los tres temas: fato profugus (v. 2), saeuae memorem Iunonis iram (v. 4), tot adire labores / impulerit (vv. 10-11). 